\title{
Discomfort, Expectations and Experiences during Treatment of Class II Malocclusion with Clear Block and Twin Block Appliance - A Pilot Survey
}

\author{
Navjeet Singh Gurudatta ${ }^{1}$, Ranjit H. Kamble², Jimmy K. Sangtani ${ }^{3}$, Zynul A. John ${ }^{4}$, Monika M. Ahuja ${ }^{5}$, Prutha G. Khakhar
}

1, 2,3,4,5, 6 Department of Orthodontics and Dentofacial Orthopaedics, Sharad Pawar

Dental College and Hospital, Sawangi, Maharashtra, India.

\section{ABSTRACT}

\section{BACKGROUND}

Skeletal class II division 1 malocclusion is an antero posterior discrepancy between maxilla and mandible which is usually treated by functional appliances when the patient is in the growing phase. It has been shown that these functional orthodontic appliances may lead to pressure on the oral mucosa, soft tissue tension, oral constriction, toothache and pain. They may also lead to fatigue or to functional speech and respiratory disorders, and they may affect the appearance of the face. All of these undesired consequences affect the patients' degree of compliance in a negative manner, and may in turn affect the patients' perception towards the treatment. This study was conducted to investigate patient perception of treatment need, appliance acceptance, expectations of treatment influence on oral health, value of dental aesthetics and information concerning treatment procedures.

\section{METHODS}

Total 30 samples were selected 15 samples were cases treated with twin block appliance and other 15 samples were treated with clear block appliance. After 8 months of treatment, a questionnaire survey was conducted assessing discomfort, expectations and experiences of all patients being treated with clear block appliance and twin block appliance.

\section{RESULTS}

Clear block seemed to be better with regard to all the parameters used in the study but on statistical analysis the difference between the two groups was insignificant.

\section{CONCLUSIONS}

Clear block appliance was designed to increase the compliance of the patient. However, clear block and twin block appliance have similar effects.
Corresponding Author: Dr. Navjeet Singh Gurudatta, Department of Orthodontics and Dentofacial Orthopaedics, Sharad Pawar Dental College and Hospital, Sawangi, Maharashtra, India. E-mail: nvjet.sngh4u@gmail.com

DOI: $10.14260 / \mathrm{jemds} / 2021 / 227$

How to Cite This Article: Gurudatta NS, Kamble RH, Sangtani JK, et al. Discomfort, expectations and experiences during treatment of class II malocclusion with clear block and twin block appliance - a pilot survey. J Evolution Med Dent Sci 2021;10(15):1064-1068, DOI: 10.14260/jemds/2021/227

Submission 04-08-2020, Peer Review 26-01-2021, Acceptance 04-02-2021, Published 12-04-2021.

Copyright (c) 2021 Navjeet Singh Gurudatta et al. This is an open access article distributed under Creative Commons Attribution License [Attribution 4.0 International (CC BY 4.0)]

\section{KEY WORDS}

Class II, Clear Block, Twin Block 


\section{BACKGROUND}

Skeletal class II division 1 malocclusion is an antero posterior (AP) discrepancy between maxilla and mandible which often results from either maxillary prognathism or mandibular retrognathism or a combination of both. In cases of growing class II division 1 with functional retrusion of lower jaw, 1 treatment can be done either by using removable myofunctional appliance or fixed functional appliance.

The term functional appliance refers to a variety of orthodontic appliances designed to induce a change in activity of the various muscle groups that influence the function and the position of the mandible in order to transmit forces to the dentition and the basal bone. ${ }^{2}$ Altering the sagittal and vertical mandibular position causes changes in muscular forces and result in orthopaedic and orthodontic changes. ${ }^{3-5}$ During functional appliance treatment, this alteration in forces may lead to pain and discomfort at various levels. It has been shown that the orthodontic appliances may lead to pressure on the oral mucosa, soft tissue tension, oral constriction, toothache and pain.6,7 It has also been noted that removable appliances additionally may lead to fatigue or to functional speech and respiratory disorders, and they may affect the appearance of the face. ${ }^{8}$

Informing patients about possible problems and discomfort throughout functional treatment is beneficial in order to enhance the appliance efficiency and patient compliance. ${ }^{9}$ It is known that patient cooperation may decline due to discomforts such as narrowing of the oral cavity and soft tissue irritation when orthodontic appliances are implemented. Speech difficulties can also be observed among patients, and the appearance of the appliances may be unpleasant during social interactions.10,11,12 All of these undesired consequences affect the patients degree of compliance in a negative manner, and it is necessary to explain possible discomforts and how to eliminate them. ${ }^{13,14}$ In this sense, it is important that the orthodontists select the suitable appliance for the patient. 15

While selecting the functional orthodontic appliances, acceptability and intraoral condition of the patients should be taken into consideration. One way of assessing the acceptability of an appliance is to conduct surveys asking about the experiences of patients and their parents. ${ }^{16,17}$

Several types of myofunctional appliances are presented in the literature for the correction of class II division 1 malocclusion which are aimed at improving skeletal imbalances, arch form and the orofacial function.

To increase the compliance of the patient, clear block appliance was designed in our department. ${ }^{18}$ It has a great advantage of being highly aesthetic and retentive, thereby improving the patient compliance manifold. It is less bulky and as this appliance consists of the thermoplastic material involving whole of the maxillary and mandibular dental arch, there is no development of posterior open bite, which is a routine finding with other mandibular advancement appliances. Moreover, because of lower incisor covering, there is decreased tendency of proclination of mandibular incisors, resulting in increased stability of mandibular incisors. Also, this appliance is easy to fabricate and requires minimal laboratory procedure, thus it is more cost effective. However, there is no much data available on the acceptance of this appliance by the patients.

Therefore, this study was conducted to investigate patient perception of treatment need, appliance acceptance, expectations of treatment influence on oral health, value of dental aesthetics and information concerning treatment procedures.

\section{METHODS}

This descriptive analytical study was conducted from October 2017 to July 2018 in the Department of Orthodontics and Dentofacial Orthopaedics. Ethical clearance was received from the ethical committee of Sharad Pawar Dental College and Hospital. 30 samples were selected from the cases seeking myofunctional treatment in the Department of Orthodontics and Dentofacial Orthopaedics. They were divided into 2 groups

1. Cases treated with twin block appliance - 15 of total sample

2. Cases treated with clear block appliance - 15 of total sample

After 8 months of treatment, a questionnaire survey was conducted assessing discomfort, expectations and experiences of all patients being treated with clear block appliance and twin block appliance. The questionnaire was validated by Dental Educational Unit (DEU). All the questions were close ended. It was a descriptive analytical study.

The questionnaire consisted of 17 different questions like does the appliance fall while sleeping, why did the patient opt for the particular treatment, any difficulties faced while sleeping or eating food, how was the experience with the appliance any pain or discomfort or did the appliance make the patient feel socially acceptable or not or did the patient had any problems with the speech or any gag reflex was experienced, was the appliance easy to wear, did it break got removed or during the treatment and how would the patient rate the appliance on wearing it. All the questions were graded as -

1. Very Good

2. Good

3. Average

4. Poor

The grading was based on the 4 point Likert scale. The data was collected by the authors. The questionnaires were given to the patients and got them filled at the specified time when they reported to the department.

\section{Statistical Analysis}

Statistical analysis was done by using descriptive and inferential statistics using chi-square test and software used in the analysis were Statistical Package for the Social Sciences (SPSS) 22.0 version and GraphPad Prism 7.0 version and $\mathrm{P}<$ 0.05 was considered as level of significance.

The questionnaire was validated by the institutional ethical committee. 


\section{RESULTS}

As per our questionaries' we analysed the experiences of patients wearing clear block appliances. It was found that 80 percent of patients wearing clear block, experienced good fit of the appliance whereas 67 percent of patients wearing twin block experienced good fit of the appliance (Table 1, Q1).
When questions regarding the comfort of the patient with this appliance was analysed (Table 1, Q3, 7, 8, 14), about $80 \%$ of the patients rarely experienced any difficulty in falling asleep while wearing the clear block appliance and 60 percent of patients wearing twin block appliance experienced any difficulty while asleep.

\begin{tabular}{|c|c|c|c|c|c|}
\hline Sl. No. & Question & Twin Block & Clear Block & $\chi 2$-Value & P-Value \\
\hline \multirow{4}{*}{ Question 1} & Very good & $5(33.33 \%)$ & $6(40 \%)$ & \multirow{4}{*}{0.71} & \multirow{4}{*}{0.86, NS } \\
\hline & Good & $5(33.33 \%)$ & $6(40 \%)$ & & \\
\hline & Average & $3(20 \%)$ & $2(13.33 \%)$ & & \\
\hline & Poor & $2(13.33 \%)$ & $1(6.67 \%)$ & & \\
\hline \multirow{4}{*}{ Question 2} & Very good & $11(73.33 \%)$ & $11(73.33 \%)$ & \multirow{4}{*}{0.00} & \multirow{4}{*}{$1.00, \mathrm{NS}$} \\
\hline & Good & $0(0 \%)$ & $0(0 \%)$ & & \\
\hline & Average & $0(0 \%)$ & $0(0 \%)$ & & \\
\hline & Poor & $4(26.67 \%)$ & $4(26.67 \%)$ & & \\
\hline \multirow{4}{*}{ Question 3} & Very good & $2(13.33 \%)$ & $4(26.67 \%)$ & \multirow{4}{*}{4.09} & \multirow{4}{*}{0.25, NS } \\
\hline & Good & $6(40 \%)$ & 8 (53.33 \%) & & \\
\hline & Average & $3(20 \%)$ & $0(0 \%)$ & & \\
\hline & Poor & $4(26.67 \%)$ & $3(20 \%)$ & & \\
\hline \multirow{4}{*}{ Question 4} & Very good & $3(20 \%)$ & $4(26.67 \%)$ & \multirow{4}{*}{0.90} & \\
\hline & Good & $5(33.33 \%)$ & $6(40 \%)$ & & \\
\hline & Average & $3(20 \%)$ & $3(20 \%)$ & & $0.82, \mathrm{NS}$ \\
\hline & Poor & $4(26.67 \%)$ & $2(13.33 \%)$ & & \\
\hline & Very good & $3(20 \%)$ & $8(53.33 \%)$ & & \\
\hline & Good & $6(40 \%)$ & $3(20 \%)$ & & \\
\hline Question 5 & Average & $4(26.67 \%)$ & $2(13.33 \%)$ & 3.93 & 0.26 , NS \\
\hline & Poor & $2(13.33 \%)$ & $2(13.33 \%)$ & & \\
\hline & Very good & $3(20 \%)$ & $6(40 \%)$ & & \\
\hline & Good & $5(33.33 \%)$ & $3(20 \%)$ & & \\
\hline Question 6 & Average & $4(26.67 \%)$ & $4(26.67 \%)$ & 1.70 & $0.63, \mathrm{NS}$ \\
\hline & Poor & $3(20 \%)$ & $2(13.33 \%)$ & & \\
\hline & Very good & $6(40 \%)$ & $4(26.67 \%)$ & & \\
\hline & Good & $2(13.33 \%)$ & $7(46.67 \%)$ & & \\
\hline Question 7 & Average & $3(20 \%)$ & $4(26.67 \%)$ & 7.32 & $0.06, \mathrm{NS}$ \\
\hline & Poor & $4(26.67 \%)$ & $0(0 \%)$ & & \\
\hline & Very good & $3(20 \%)$ & $10(66.67 \%)$ & & \\
\hline & Good & $8(53.33 \%)$ & 2 (13.33 \%) & & \\
\hline Question 8 & Average & $2(13.33 \%)$ & $2(13.33 \%)$ & 7.70 & $0.05, \mathrm{NS}$ \\
\hline & Poor & $2(13.33 \%)$ & $1(6.67 \%)$ & & \\
\hline & Very good & $4(26.67 \%)$ & $6(40 \%)$ & & \\
\hline & Good & $5(33.33 \%)$ & $4(26.67 \%)$ & & \\
\hline Question 9 & Average & $4(26.67 \%)$ & $3(20 \%)$ & 0.65 & 0.88, NS \\
\hline & Poor & $2(13.33 \%)$ & $2(13.33 \%)$ & & \\
\hline & Very good & $0(0 \%)$ & $0(0 \%)$ & & \\
\hline & Good & $8(53.33 \%)$ & $9(60 \%)$ & & \\
\hline Question 10 & Average & $2(13.33 \%)$ & $4(26.67 \%)$ & 2.01 & $0.36, \mathrm{NS}$ \\
\hline & Poor & $5(33.33 \%)$ & $2(13.33 \%)$ & & \\
\hline & Very good & $4(26.67 \%)$ & $5(33.33 \%)$ & & \\
\hline & Good & $4(26.67 \%)$ & $5(33.33 \%)$ & & \\
\hline Question 11 & Average & $4(26.67 \%)$ & $3(20 \%)$ & 0.56 & 0.90, NS \\
\hline & Poor & $3(20 \%)$ & $2(13.33 \%)$ & & \\
\hline & Very good & $4(26.67 \%)$ & $7(46.67 \%)$ & & \\
\hline & Good & $4(26.67 \%)$ & $4(26.67 \%)$ & & \\
\hline Question 12 & Average & $4(26.67 \%)$ & $3(20 \%)$ & 1.96 & 0.58, NS \\
\hline & Poor & $3(20 \%)$ & $1(6.67 \%)$ & & \\
\hline & Very good & $4(26.67 \%)$ & $7(46.67 \%)$ & & \\
\hline Question 13 & Good & $5(33.33 \%)$ & $4(26.67 \%)$ & 1.92 & \\
\hline Question 13 & Average & $3(20 \%)$ & $3(20 \%)$ & 1.92 & $0.58, \mathrm{NS}$ \\
\hline & Poor & $3(20 \%)$ & $1(6.67 \%)$ & & \\
\hline & Very good & $3(20 \%)$ & 7 (46.67 \%) & & \\
\hline & Good & $6(40 \%)$ & $4(26.67 \%)$ & & \\
\hline Question 14 & Average & $4(26.67 \%)$ & $3(20 \%)$ & 2.47 & $0.47, \mathrm{NS}$ \\
\hline & Poor & $2(13.33 \%)$ & $1(6.67 \%)$ & & \\
\hline & Very good & $2(13.33 \%)$ & $5(33.33 \%)$ & & \\
\hline & Good & $7(46.67 \%)$ & $6(40 \%)$ & & \\
\hline Question 15 & Average & $4(26.67 \%)$ & $3(20 \%)$ & 1.83 & 0.60, NS \\
\hline & Poor & $2(13.33 \%)$ & $1(6.67 \%)$ & & \\
\hline & Very good & $0(0 \%)$ & $0(0 \%)$ & & \\
\hline & Good & $1(6.67 \%)$ & $1(6.67 \%)$ & & \\
\hline Question 16 & Average & $8(53.33 \%)$ & $10(66.67 \%)$ & 0.62 & 0.73, NS \\
\hline & Poor & $6(40 \%)$ & $4(26.67 \%)$ & & \\
\hline & Very good & $2(13.33 \%)$ & $3(20 \%)$ & & \\
\hline Ouestion 17 & Good & $6(40 \%)$ & $7(46.67 \%)$ & 127 & \\
\hline Question 17 & Average & $4(26.67 \%)$ & $4(26.67 \%)$ & 1.21 & $0.73, \mathrm{NS}$ \\
\hline & Poor & $3(20 \%)$ & $1(6.67 \%)$ & & \\
\hline & able 1. Co & $\begin{array}{l}\text { comfort, Exp } \\
\text { lusion with } 1\end{array}$ & $\begin{array}{l}\text { Experiences } \\
\text { d Clear Block }\end{array}$ & atm & \\
\hline
\end{tabular}




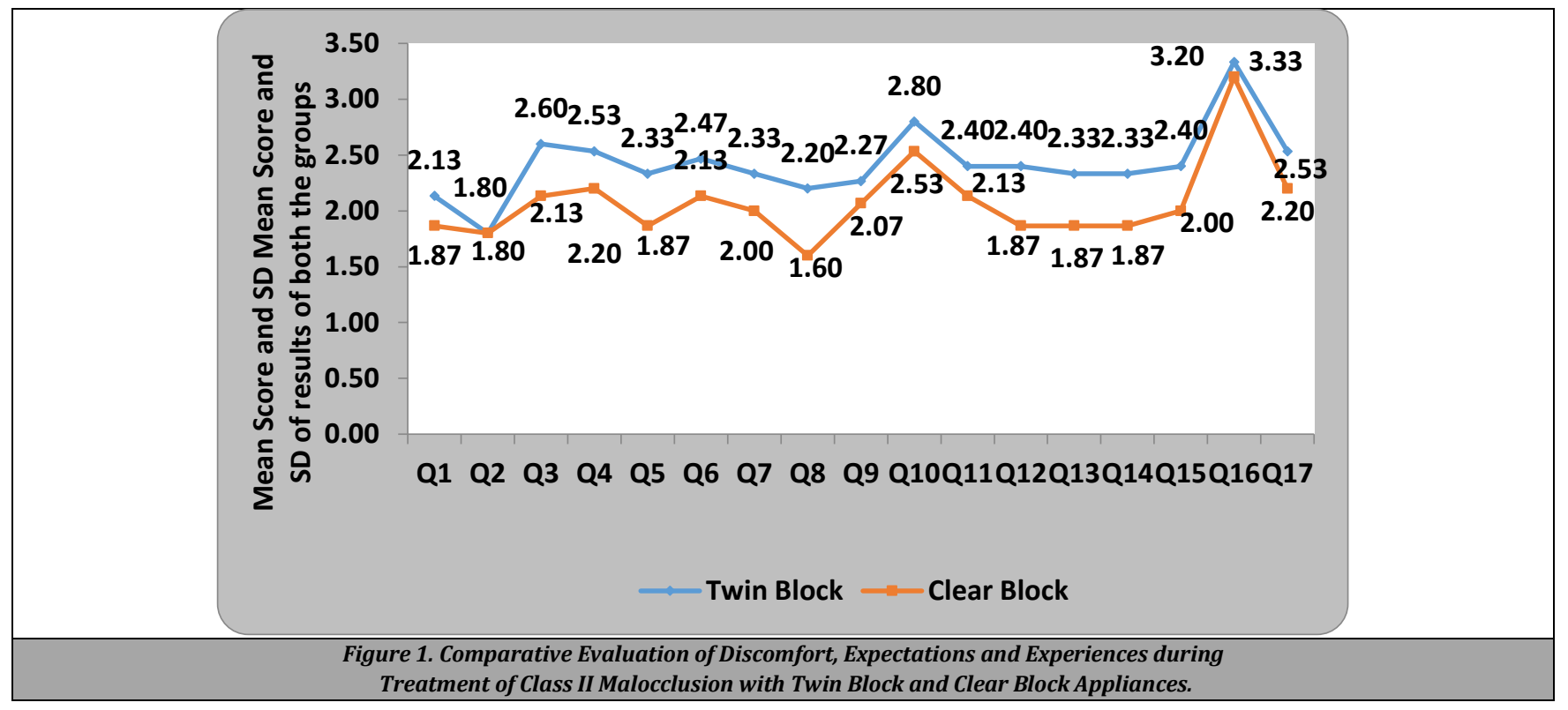

$72 \%$ of the patients were quite comfortable with the use of clear block appliance. $53 \%$ of patients wearing twin block were comfortable with the appliance (Q3).

No discomfort or slight amount of discomfort was noted in around $80 \%$ of the patients wearing clear block and in $73 \%$ of patients wearing twin block (Q8). It was noted that $72 \%$ and $60 \%$ of the patients hardly complained of any injury by any part of the clear block and twin block appliance respectively (Q14).

When speech was noted, $60 \%$ and $53 \%$ of patients rarely had any speech discomfort in clear block and twin block appliance respectively (Q10) whereas $67 \%$ and $60 \%$ almost took around a week to adapt to proper acceptable speech in clear block and twin block appliance respectively (Q16).

About $66 \%$ and $53 \%$ of the patients rarely had any difficulty while mastication in clear block and twin block appliance respectively (Q4). $73 \%$ clear block wearers and 60 $\%$ twin block wearers found the appliance socially acceptable

(Q5) $60 \%$ of clear block patient and $53 \%$ of twin block patient experienced less breakages with appliance (Q6.). $66 \%$ of the clear block and $52 \%$ of twin block patients rarely forgot to wear the appliance (Q11).

$72 \%$ of clear block and $55 \%$ of twin block patients found it easy to wear and remove the appliance $(\mathrm{Q} 12,13) .73 \%$ of clear block and $60 \%$ of twin block patients wearing appliance were happier with the aesthetic appeal (Q15) and understood the need to wear them for future improved aesthetics.

(Q2) $66 \%$ of clear block and $53 \%$ of twin block patients rarely experienced gag reflex (Q17) and the overall experience was good with the use of clear block and twin block appliance (Q9). However, even though the clear block seems better with all these parameters on statistical analysis, the difference between the two groups was insignificant.

\section{DISCUSSION}

Patient response is an important aspect in myofunctional therapy. Patients may experience many difficulties and discomfort at various levels. Pain, toothache, difficulty in speech, oral ulcers due to pressure and impingement of appliance on the soft tissues are some of the difficulties experienced by the patient. ${ }^{19}$ Also, the bulky appearance of the appliance makes it less socially acceptable.

Clear block appliance, being one of the newer functional appliances, was expected to have all the problems related to functional appliance.

From the results obtained, it was concluded that patients of both groups were comfortable with the appliance as it had a proper fit in the mouth. However, number of patients wearing clear block appliance with positive feedback were more than twin block appliance. This result contraindicates literature which mentioned that functional appliance cause discomfort to the patients. Akshay et al. (2017) ${ }^{20}$ evaluated patients' response in twin block appliance and concluded that some amount of discomfort was experienced by the patients during the meals. Although, in a randomised trial control study by Hans George Sergle et al. (2000) ${ }^{21}$ stated that patient's reaction to the treatment was responsible for the amount of acceptability and adaptation of the appliance with comfort.

Speech acceptability is the second most problem faced by the patients. From the results obtained from this study, majority of the patients from both the groups had acceptable speech and this acceptability was observed after 1 week of appliance wear. It was observed that patients wearing clear block appliance had greater amount of acceptability than patients wearing twin block appliance but was not significant. Previous studies have concluded that there is high degree of speech impairment in appliances such as bionator and headgear. ${ }^{21}$ Also, functional appliance such as twin block led to speech impairment. ${ }^{19}$

Thus, it can be concluded from the above findings that speech impairment was observed considerably less in clear block appliance than twin block appliance but no significant difference was observed between the two.

Clear block and twin block appliance were also found to be socially acceptable among the patients and also there was an ease of mastication. More acceptance was seen with patients wearing clear block appliance but no significant difference was found between clear block and twin block. According to some studies, compliance with the treatment of functional appliance 
was related to the social acceptance of the appliance. All the complaints of the patients were related to its social acceptability and not due to discomfort or appliance

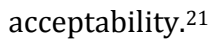

Since clear block appliance does not consist of any wire component, its wear and removal were found to be easy with less breakages and damage to the appliance. Other functional appliances such as bionator, activator, twin block consist of wire components and thus their wear and removal were difficult with considerably more chances of breakages and damage to these appliances. Also, it was observed that patients with clear block appliance experienced considerably lesser gag reflex than patients wearing twin block appliance.

From the above observations, it was concluded that patients with clear block appliances were overall happy, satisfied and content with the appliance when compared with patients with twin block appliance. This positive response of the patients increases the acceptability towards the treatment pertaining to skeletal corrections.

\section{CONCLUSIONS}

Clear block appliance was designed to increase the compliance of the patient. It proved to be the best alternative to other myofunctional appliances. However, clear block and twin block appliance have similar effects. Acceptability and satisfaction of both the appliances is similar among the patients.

Data sharing statement provided by the authors is available with the full text of this article at jemds.com.

Financial or other competing interests: None.

Disclosure forms provided by the authors are available with the full text of this article at jemds.com.

\section{REFERENCES}

[1] Zymperdikas VF, Koretsi V, Papageorgiou SN, et al. Treatment effects of fixed functional appliances in patients with class II malocclusion: a systematic review and meta-analysis. Eur J Orthod 2015;38(2):113-26.

[2] Yassaei S, Bahrololoomi Z, Sorush M. Changes of tongue position and oropharynx following treatment with functional appliance. J Clin Pediatr Dent 2007;31(4):28790.

[3] Bishara SE, Ziaja RR. Functional appliances: a review. Am J Orthod Dentofacial Orthop 1989;95(3):250-8.

[4] Patel HP, Moseley HC, Noar JH. Cephalometric determinants of successful functional appliance therapy. Angle Orthod 2002;72(5):410-7.

[5] Pangrazio-Kulbersh V, Berger JL, Chermak DS, et al. Treatment effects of the mandibular anterior repositioning appliance on patients with Class II malocclusion. Am J Orthod Dentofacial Orthop 2003;123(3):286-95

[6] Johnson PD, Cohen DA, Aiosa L, et al. Attitudes and compliance of pre-adolescent children during early treatment of class II malocclusion. Clin Orthod Res 1998;1(1):20-8.

[7] Hedlund C, Feldmann I. Success rate, costs and long-term stability of treatment with activator/headgear combinations. Swed Dent J 2016;40(1):67-77.

[8] Idris G, Hajeer MY, Al-Jundi A. Acceptance and discomfort in growing patients during treatment with two functional appliances: a randomised controlled trial. Eur J Paediatr Dent 2012;13(3):219-24.

[9] Lewis HG, Brown WA. The attitude of patients to the wearing of a removable orthodontic appliance. Br Dent J 1973;134(3):87-90.

[10] Oliver RG, Knapman YM. Attitudes to orthodontic treatment. Br J Orthod 1985;12(4):179-88.

[11] Sergl HG, Zentner A. A comparative assessment of acceptance of different types of functional appliances. Eur J Orthod 1998;20(5):517-24.

[12] Egolf RJ, BeGole EA, Upshaw HS. Factors associated with orthodontic patient compliance with intraoral elastic and headgear wear. Am J Orthod Dentofacial Orthop 1990;97(4):336-48.

[13] Doll GM, Zentner A, Klages U, et al. Relationship between patient discomfort, appliance acceptance and compliance in orthodontic therapy. J Orofac Orthop 2000;61(6):398413.

[14] Sergl HG, Klages U, Zentner A. Pain and discomfort during orthodontic treatment: causative factors and effects on compliance. Am J Orthod Dentofacial Orthop 1998;114(6):684-91.

[15] Gosney MB. An investigation into factors which may deter patients from undergoing orthodontic treatment. Br J Orthod 1985;12(3):133-8.

[16] Bowman AC, Saltaji H, Flores-Mir C, et al. Patient experiences with the forsus fatigue resistant device. Angle Orthod 2013;83(3):437-46.

[17] De Oliveira CM, Sheiham A. Orthodontic treatment and its impact on oral health-related quality of life in Brazilian adolescents. Journal of Orthodontics 2004;31(1):20-7.

[18] Sharma N, Shrivatav S, Kamble R, et al. A tailored approach for growth modification: an innovative approach. World Journal of Dentistry 2017;8(4):334-42.

[19] Lena Y, Bozkurt AP, Yetkiner E. Patients and parents perception of functional appliances: a survey study. Turk J Orthod 2017;30(2):33-41.

[20] Thirumurthi AS, Felicita AS, Jain RK. Patient's psychological response to twin - block therapy. World Journal of Dentistry 2017;8(4):327-30.

[21] Sergl HG, Klages U, Zentner A. Functional and social discomfort during orthodontic treatment-effects on compliance and prediction of patients adaptation by personality variables. Eur J Orthod 2000;22(3):307-15. 